\title{
REPORT OF A CASE WITH CONGENITAL ABSENCE OF THE SPLEEN AND LAEVOCARDIA
}

\author{
BY
}

\author{
J. NIHOYANNOPOULOS, L. ZANNOS, C. OECONOMOU-MAVROU, \\ AND E. STATHEROU \\ From the Paediatric Clinic of Athens University
}

(RECEIVED FOR PUBLICATION NOVEMBER 21, 1955)

Congenital absence of the spleen is a rare anomaly. The first case to be described in infancy is that of Martin (1826). At necropsy a partial situs inversus of the viscera and congenital malformations of the heart were found.

Polhemus and Schafer (1952) reviewed the literature up to 1952 and found 12 cases of congenital absence of the spleen in infants. To these they added four cases of their own. In all cases congenital malformations of the heart were also present. They consisted of pulmonary stenosis or atresia, anomalies of the great vessels and atrioventricularis communis. In eight of the 16 cases there was partial or total situs inversus of the viscera, while the heart was on the left side. This syndrome is known as laevocardia.

In a recent article Bush and Ainger (1955) found five additional cases of congenital absence of the spleen in infants in the literature, to which they added one of their own. It has been possible for us to ascertain the presence of laevocardia in only two of these cases, the authors' own patient and one of the patients described by Gasser and Willi (1952), the remaining bibliography not being available to us. Bush and Ainger (1955) drew attention to the characteristic blood picture of their patient which permitted the ante-mortem diagnosis of the absence of the spleen. The picture is similar to the one observed in patients who have undergone splenectomy and is characterized by the presence of Howell-Jolly bodies and Heinz bodies in the red cells, normoblastaemia, target cells, and siderocytes. The only two other cases of splenic agenesis diagnosed before death are those of Gasser and Willi (1952). The diagnosis was made on the basis of the haematological findings. In reviewing the literature on splenic agenesis we have come across two other cases in infants, recently described by Baumann (1954). Both had an associated partial situs inversus of the viscera and anomalies of the heart. The position of the heart was normal in one of the cases.

The number of established cases of splenic agenesis in infants is therefore 24 up to the present day. In 11 of them at least laevocardia was present. In adults splenic agenesis has usually been an isolated finding although in some other minor congenital anomalies have also been present. According to Bush and Ainger (1955) 10 adult cases have been reported in the literature.

The purpose of this paper is to present another case of splenic agenesis which was suspected before death on the basis of the blood picture and to call attention to the frequency with which laevocardia is associated with this anomaly.

\section{Case Report}

G. H., a 2-month-old girl, was admitted to the Paediatric Clinic of Athens University because of cyanosis present since birth, which was more pronounced during crying, and failure to gain weight normally.

The patient was the third child of healthy parents. One sibling died at the age of 3 days, cause unknown, and the other is alive and well.

Birth weight was 2,100 g., weight on admission 2,840 g., and length $49 \mathrm{~cm}$. Physical examination showed a moderately cyanotic and physically retarded infant. The pulse was strong in the upper and lower extremities. Examination of the heart revealed no thrills and no murmurs. The sounds were forceful. The lungs were clear. The liver was felt $1.5 \mathrm{~cm}$. below the right costal margin and the spleen was believed palpable.

Clinical Investigations.-Radiology showed marked cardiac enlargement to the left with an upturned apex. An electrocardiogram showed right auricular hypertrophy and dilatation, slight right axis deviation, marked clockwise rotation, and right ventricular hypertrophy.

Haematological Investigations.-Blood examination: red cells 5,000,000/c.mm.; haemoglobin 11.8 g./ 
$100 \mathrm{ml}$; M.C.H.C. $27 \%$; M.C.H. $23 \gamma \gamma$; haematocrit $44 \%$; white cells $25,000 /$ c.mm. (neutrophils $70 \%$, eosinophils $2 \%$, lymphocytes $25 \%$, monocytes $3 \%$ ); reticulocytes $6 \%$. A blood film showed that most of the red cells were large target cells and HowellJolly bodies were not observed. The nucleated red cells were mostly mature with only occasional proerythroblasts. Thrombocytes were present in large clumps. There were 400 normoblasts per 100 white blood cells. Vital staining of red cells revealed the presence of many Heinz bodies. Siderocytes were absent and there was no sickling. The Wassermann reaction was negative. Paper electrophoresis showed a normal haemoglobin pattern ; alkali-resistant haemoglobin 7\% (within normal limits for age); serum bilirubin $0.6 \mathrm{mg}$. $/ 100 \mathrm{ml}$.; the bone marrow showed an erythro-myeloid ratio of 3 to 1 .

The patient was thought at first to have congenital leukaemia, possibly erythrolaemia, but examination of the bone marrow, which showed only a normoblastic hyperplasia, ruled it out. The congenital haemolytic anaemias were also excluded on the basis of a normal alkali-resistant haemoglobin and an electrophoretically normal haemoglobin. Congenital spherocytosis. congenital non-spherocytic haemolytic anaemia, and elliptocytosis were not considered because the blood smear was negative for spherocytes or elliptocytes and such a high normoblastaemia is not found in these diseases unless the patient is in a crisis. Splenic agenesis was suspected two days before the death of the patient, at which time the baby was in such bad condition that she could not be taken off oxygen and given a barium meal. Situs inversus of the stomach and duodenum were therefore not diagnosed before death. Despite the lack of Howell-Jolly bodies and siderocytes we considered splenic agenesis the most probable diagnosis, partly because of the exclusion of the common pathological conditions showing erythroblastaemia and target cells and partly because of the association of the characteristic haematological findings with severe congenital heart anomalies. For this reason we did not proceed further in our haematological study of the patient. The baby's condition became progressively worse, and she died on the twelfth day after admission.

\section{Necropsy Findings}

The body was that of a moderately cyanosed undernourished white female infant. The pericardial cavity was free of excess fluid and adhesions. The position of the heart was normal. The aorta arose from the right side of the heart. The ascending thoracic aorta ran upwards to the right and the aortic arch was seen to overly the right main bronchus. The descending thoracic aorta ran downwards to the right of the trachea and oesophagus. The right common carotid and the right subclavian arteries arose separately from the aortic arch to the right. The innominate artery arose independently from the arch to the left. It measured $0.3 \mathrm{~cm}$. in length and divided into the left common carotid and the left subclavian arteries. Into the latter opened the relatively widely patent ductus arteriosus.

The aortic valve ring measured $3 \mathrm{~cm}$. in circumference and its three cusps were normal. The coronary arteries arose from their usual positions and had a normal course. The short and hypoplastic pulmonary artery measured $1 \mathrm{~cm}$. in length and $0.2 \mathrm{~cm}$. in circumference. It was situated behind and to the left of the aorta. Its point of origin from the posterior wall of the aorta was atretic and no communication between the lumen of the aorta and the pulmonary artery could be demonstrated. The pulmonary artery divided into right and left hypoplastic branches, each entering the corresponding lung. The patent ductus arteriosus opened into the pulmonary artery at its bifurcation.

There was no interventricular septum, and the aorta arose from the upper part of the single ventricular cavity (Fig. 1). The right atrium opened into this common ventricle through a normal tricuspid valve measuring $4.5 \mathrm{~cm}$. in circumference. Th\& venae cavae entered the right atrium normally. The right auricular appendage was well developed. The left auricle was moderately hypoplastic and, due tộ. a mitral valve atresia, no communication with the ventricle could be demonstrated. There was almost no inter-auricular septum, a rudimentary septum in the form of a ridge extending from the upper posterior wall downwards and forwards.

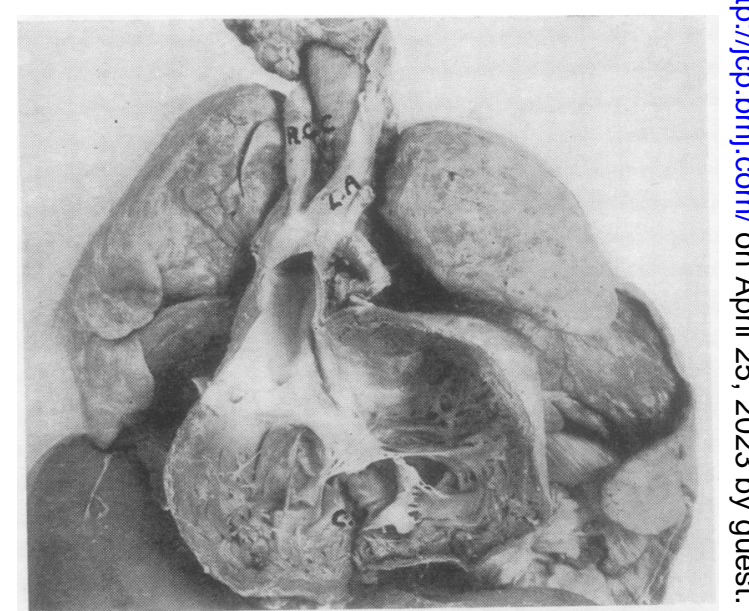

FIG. 1.-Normal position of the heart. No interventricular septum. Transposition of the aorta. LA = Left-sided innominate $O$ artery, $\mathbf{R C C}=$ right common carotid artery, $\mathrm{CV}=$ common $\mathbb{D}$ ventricle. 


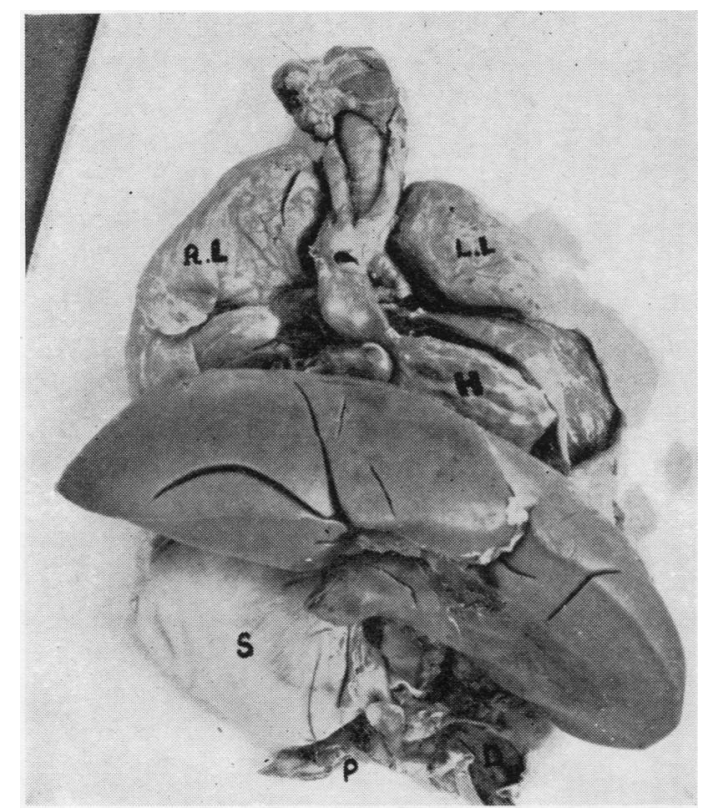

FIG. 2.-The liver occupies the entire upper part of the abdominal cavity. The stomach is on the right. There is inversion of the pancreas, the tail pointing to the right below the stomach. $R L=$ right lung, $L L=$ left lung, $S=$ stomach, $D=$ duodenum, $\mathbf{P}=$ pancreas, $\mathbf{H}=$ heart .

Both pleural cavities were free from excess fluid and adhesions. Both lungs had three lobes: their parenchyma was oedematous and markedly congested. After careful search no spleen or accessory spleens were found. The enlarged liver measured $14 \times 7 \times 4 \mathrm{~cm}$. and occupied the entire upper part of the abdominal cavity (Fig. 2). The stomach was situated on the right side below the liver. It measured $10 \mathrm{~cm}$. along the greater curvature and $4.5 \mathrm{~cm}$. along the lesser curvature. The pancreas was inverted with the head in the bend of the duodenum on the left and the tail pointing to the right behind the stomach. Both kidneys were normal.

\section{Discussion}

The necropsy findings in our patient showed that splenic agenesis was associated with laevocardia. The term "laevocardia" was first coined by Taussig (1947), who described a case of "situs inversus with a levocardia." The term means that the heart is lying on the left side while it should be lying on the right. This should be the case when all the other organs of the thoracic and abdominal cavities are inverted. However, to-day we speak of laevocardia also when the abdominal organs alone are inverted. Schmidt and Korth (1954) go even further and extend the term laevocardia to include cases where only the liver is inverted. They consider the liver the "dominating organ" because the position of the liver usually corresponds to the position of the coronary sinus. In our case the abdominal organs were inverted. The lungs were not inverted, but both were trilobulated. There was, therefore, a partial situs inversus with the heart in its normal position.

The blood findings in our patient presented three of the characteristics of splenectomized patients, namely normoblastaemia, target cells, and Heinz bodies. Howell-Jolly bodies were lacking as well as siderocytes, but the latter would have probably made their appearance if we had had the time to start iron treatment. We think we were justified in suspecting splenic agenesis despite the fact that some of the characteristic findings were missing for reasons already mentioned. For a detailed discussion of the blood findings in splenic agenesis and a description of other conditions with similar blood findings, we refer the reader to the paper by Bush and Ainger (1955).

Our patient is therefore another example of splenic agenesis associated with laevocardia. Thus at least 12 out of 25 recorded cases of splenic agenesis are associated with laevocardia. It is suggested that the ante-mortem diagnosis of splenic agenesis can be established by the finding of laevocardia, together with the characteristic blood findings described.

\section{Summary}

A case of splenic agenesis is described which was suspected before death because of the characteristic haematological findings and the associated congenital heart anomalies.

The literature on splenic agenesis is briefly reviewed and its frequent association with a special type of congenital heart anomaly, i.e., laevocardia, is emphasized.

\section{REFERENCES}

Baumann, J. (1954). Helv. paediat. Acta, 9, 199. Abstracted in Excerpta med. (Amst.), Sect. VII, 9, 251 (1955).

Bush, J., and Ainger, L. E. (1955). Pediatrics, 15, 93.

Gasser, C., and Willi, H. (1952). Helv. paediat. Acta, 7, 369.

Martin, M. G. (1826). Bull. Soc. Anat. Paris, 1, 39. Cited by Polhemus, D. W., and Schafer, W. B. (1952).

Polhemus, D. W., and Schafer, W. B. (1952). Pediatrics, 9, 696.

Schmidt, J., and Korth, C. (1954). Dtsch. Arch. klin. Med., 201, 454.

Taussig, H. B. (1947). Congenital Malformations of the Heart, p. 513. Commonwealth Fund, New York. 